\title{
Pathological and prognostic role of mdig in pancreatic cancer
}

\author{
Srinivas Ashok Kumar ${ }^{1}$, Chitra Thakur ${ }^{1}$, Lingzhi $\mathrm{Li}^{1}$, Hongjuan Cui ${ }^{2}$ and Fei Chen ${ }^{1}$ \\ ${ }^{1}$ Department of Pharmaceutical Sciences, Eugene Applebaum College of Pharmacy and Health Sciences, Wayne State \\ University, Detroit, MI, USA \\ ${ }^{2}$ State Key Laboratory of Silkworm Genome Biology, The Institute of Sericulture and Systems Biology, Southwest University, \\ Chongqing, China \\ Correspondence to: Fei Chen, email: fchen@wayne.edu
}

Keywords: pancreatic cancer, mdig, alternative splicing, immunohistochemistry, survival rate

Received: August 11,2017 Accepted: September 01, 2017 Published: September 07, 2017

Copyright: Ashok Kumar et al. This is an open-access article distributed under the terms of the Creative Commons Attribution License (CCBY), which permits unrestricted use, distribution, and reproduction in any medium, provided the original author and source are credited.

\section{ABSTRACT}

Pancreatic cancer is a highly aggressive malignant disease having very limited therapeutic options that ultimately results in its poor prognosis. It is still elusive on the etiology and tumorigenic mechanisms of pancreatic cancer. In the present report, we provide evidence showing involvement of the mineral dust-induced gene (mdig) in the pathogenesis and prognosis of the pancreatic cancer. Using immunohistochemistry approach on human pancreatic cancer tissue microarray, we found differential expression of mdig in pancreatic adenocarcinoma and normal pancreas. Based on the staining intensities of mdig in these tissue samples, we found that $12 \%$ of the cancer tissues were strongly positive for $\mathbf{m d i g}, 39 \%$ and $31 \%$ were moderately and weakly positive respectively. Several alternatively spliced mdig mRNAs were detected in the selected pancreatic cancer cell lines. Through $R 2$ platform for the patient survival analysis (http://r2.amc.nl), we found that enrichment of some specific exon of mdig predicates different survival rate of the pancreatic cancer patients. In summary, our findings may help in assessing the role of mdig in the pathogenesis of the pancreatic cancer and the prognosis of the pancreatic cancer patients.

\section{INTRODUCTION}

Pancreatic cancer is the fourth leading cause of cancer death in both men and women in the United States [1]. In 2017, it is estimated that 53,670 Americans will be diagnosed and 43,090 patients will die of pancreatic cancer [2]. Most patients were diagnosed with pancreatic ductal adenocarcinoma. The 5-year survival rate after surgical resection is $20 \%$ and for those with metastatic disease, the 5 -year survival rate is only about $2 \%$ [3]. Late detection and diagnosis has been the critical reason for poor survival rate in pancreatic cancer patients. About $85 \%$ of patients were in the advanced stages of the pancreatic cancer that is unresectable when diagnosed [1].

African Americans have appreciably higher rates of pancreatic cancer than whites. Heritable, germline mutations in p16, BRCA2 [4], and other genes appear to be associated with a total of $5 \%-10 \%$ of all pancreatic cancers, and penetrance of these mutations for the disease may be fairly low. Chronic pancreatitis of various types is associated with another $3 \%-4 \%$ of pancreatic cancer.
Apart from germline mutations or pancreatitis, the other major risk factor associated with pancreatic cancer is cigarette smoking. Earlier studies suggested that patients with pancreatic cancer who smoked cigarettes were approximately $40 \%$ increased hazard for death compared with those who never smoked, and risk tends to increase according to frequency or duration of smoking [5]. Dietary studies have shown a fairly steady pattern of increased hazard with meat or cholesterol intake and decreased risk with fruit or vegetable consumption, although causal inferences regarding these associations are still uncertain [6].

The mineral dust- induced gene (mdig) was first identified in alveolar macrophages from patients with chronic lung diseases resulting from occupational exposure to mineral dust in mining industry [7]. This gene was independently characterized in human glioblastoma cell lines with an over expression of c-myc oncogene and named as myc-induced nuclear antigen 53 (MINA 53) [8] or nucleolar protein 52 (NO52) [9]. Mdig can be induced by a number of environmental hazards, such as arsenic, 
silica, coal dust, and particulate matter PM 2.5 [10]. The mdig gene encodes a $53 \mathrm{kDa}$ protein that is involved in cell proliferation, neoplastic transformation, epigenetics, and immune regulation, and is over expressed in a variety of human neoplasms [10]. The mdig protein contains a conserved JmjC domain that is indicated in cell growth regulation, possibly through its effect on tri-methylation of lysine 9 on histone $\mathrm{H} 3$ (H3K9me3) and hydoxylase activity on ribosomal proteins $[11,12]$.

In the present study, we evaluated the expression of mdig in pancreatic adenocarcinoma cell lines at protein and mRNA levels. Using immunohistochemistry (IHC) approach, we detected expression of mdig in human pancreatic cancer tissues and assessed its association with clinicopathological features and prognosis. We showed that about $12 \%$ and $38 \%$ of total pancreatic malignant tissue were found to be strongly and moderately positive for mdig. We also demonstrated the presence of the alternatively spliced mdig mRNAs in pancreatic cancer cell lines we tested. Through R2: Genomics Analysis, we found opposite predictive power of different exon regions for the survival of the pancreatic cancer patients, which possibly suggested diversified roles of the alternatively spliced mdig mRNAs in the pathogenesis and prognosis of the pancreatic cancer.

\section{RESULTS}

\section{Expression of mdig in human pancreatic adenocarcinoma cell lines}

An over expression of mdig has been observed in a number of human cancers, implying its important role in the pathogenesis of human malignancies. To investigate whether mdig is over expressed in pancreatic cancer, the level of mdig expression was determined by western blot technique (Figure 1a). In three pancreatic cancer cell lines, Bxpc3, Aspc1 and MIAPaca2, we found that mdig protein was detected in these cell lines cultured in either presence or absence of serum. Several repeating experiments suggested that relative to the other two cell lines, the Aspc1 cells expressed lower level of mdig protein. Analysis of cell growth showed a similar proliferation rate among these three cell lines (data not shown). However,
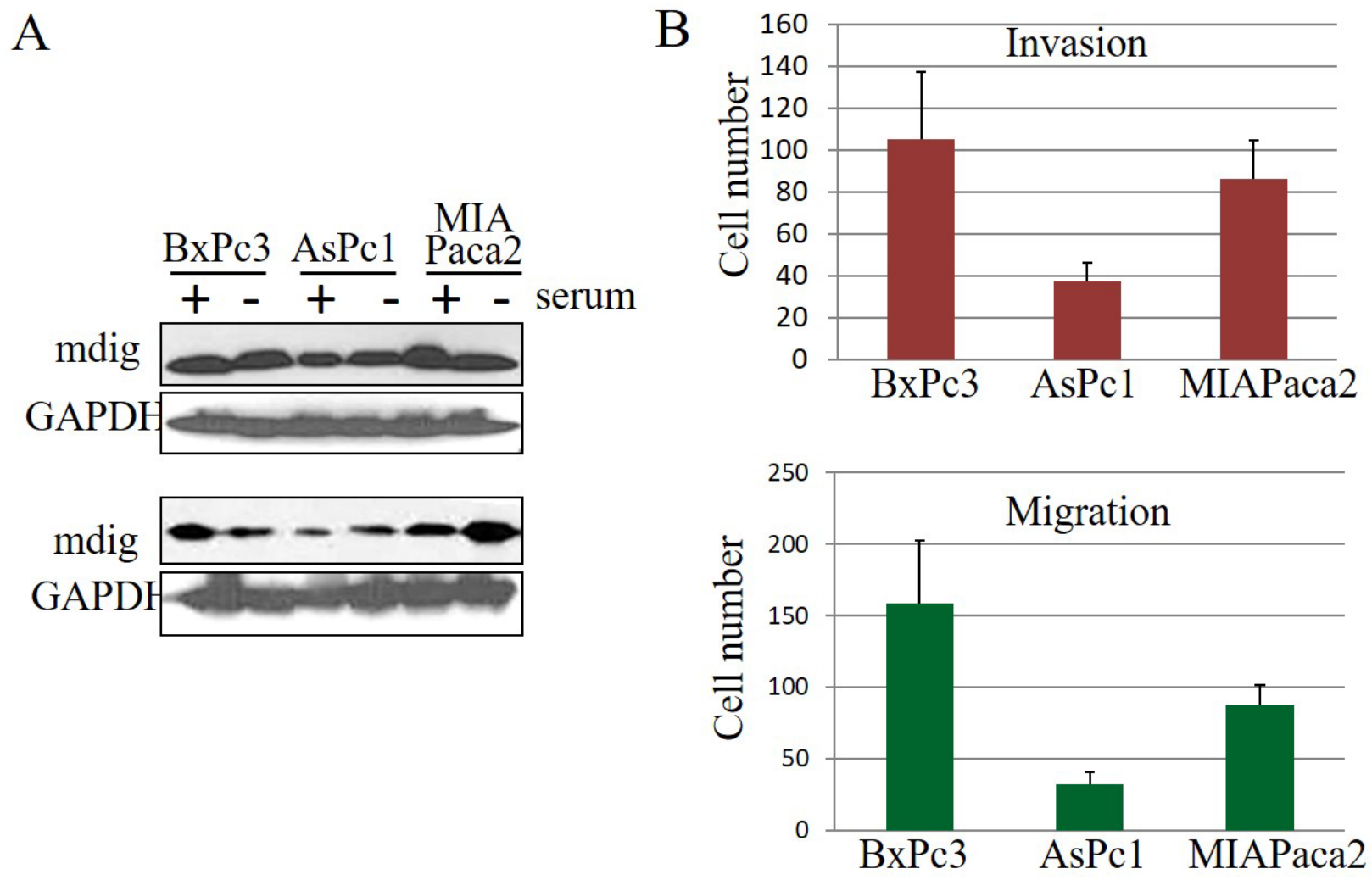

Figure 1: Expression of mdig in human pancreatic cancer cell lines. A. The indicated cells were cultured in the medium with or without $5 \%$ of serum for 24 hours. Total cell lysates were used for Western blotting using antibodies against mdig and GAPDH. Two representative results were shown. B. Cell invasion and migration assays of the indicated three pancreatic cancer cell lines. 
cell invasion and migration assays suggested that Bxpc3 cells have the highest, whereas Aspc1 cells have the lowest capabilities in migration and invasion (Figure 1b).

\section{Pancreatic adenocarcinoma cell lines express alternatively spliced mdig mRNAs}

In an effort to determine the mRNA levels of mdig among these pancreatic cancer cell lines, a traditional RT-PCR was applied for the detection of mdig mRNAs. The PCR primer set was derived from exon 1 and exon 10 regions of mdig gene, respectively, which amplifies a 1,510 bp fragment of mdig mRNA encompassing the entire open reading frame. A marginal increased expression of the constitutive full length mdig mRNA was noted among these cell lines cultured in the serum-free medium (Figure 2). We had previously reported that there are alternatively spliced mdig mRNAs in which the entire exon 2 region was spliced out with or without inclusion of an alternative exon 5' in lung epithelial cells and lung cancer cells [7]. Such alternatively spliced mdig mRNAs with sizes around 500 to $650 \mathrm{bp}$ were detected in all of these pancreatic cancer cell lines (Figure 2). In contrast to the constitutive full length $1,510 \mathrm{bp}$ mdig mRNA, the expression level of the alternatively spliced mdig mRNAs was decreased in the cells cultured in serum-free medium, suggesting different regulatory mechanisms for the expression of the constitutive full length and alternatively spliced mdig mRNAs.

\section{Correlation of mdig expression and the pathogenesis of pancreatic cancer}

We and others had demonstrated an association of mdig expression and the pathogenesis of lung cancer, breast cancer and other cancers. To determine whether there is a correlation between mdig expression and the clinical characteristics of the human pancreatic cancer, we measured the protein level of mdig among the pancreatic tissues through immunohistochemistry on a tissue microarray containing 42 cases of pancreatic cancer tissues and 6 normal pancreatic tissues. Based on the staining intensities of mdig, we found that in the normal pancreatic tissues $34 \%$ was moderately positive and $66 \%$ was weakly positive, no strongly positive staining of mdig was detected (Figure 3a). However, in the pancreatic malignant tissue, we found $12 \%$ strong positive, $39 \%$ moderately positive, $31 \%$ weakly positive and $18 \%$ negative (Figure $3 b$ ).

To further evaluate mdig expression and the pathogenesis of pancreatic cancer tissues, we determined the protein levels of mdig by IHC analysis among the pancreatic cancer tissues with well-defined clinicopathological features. The association between
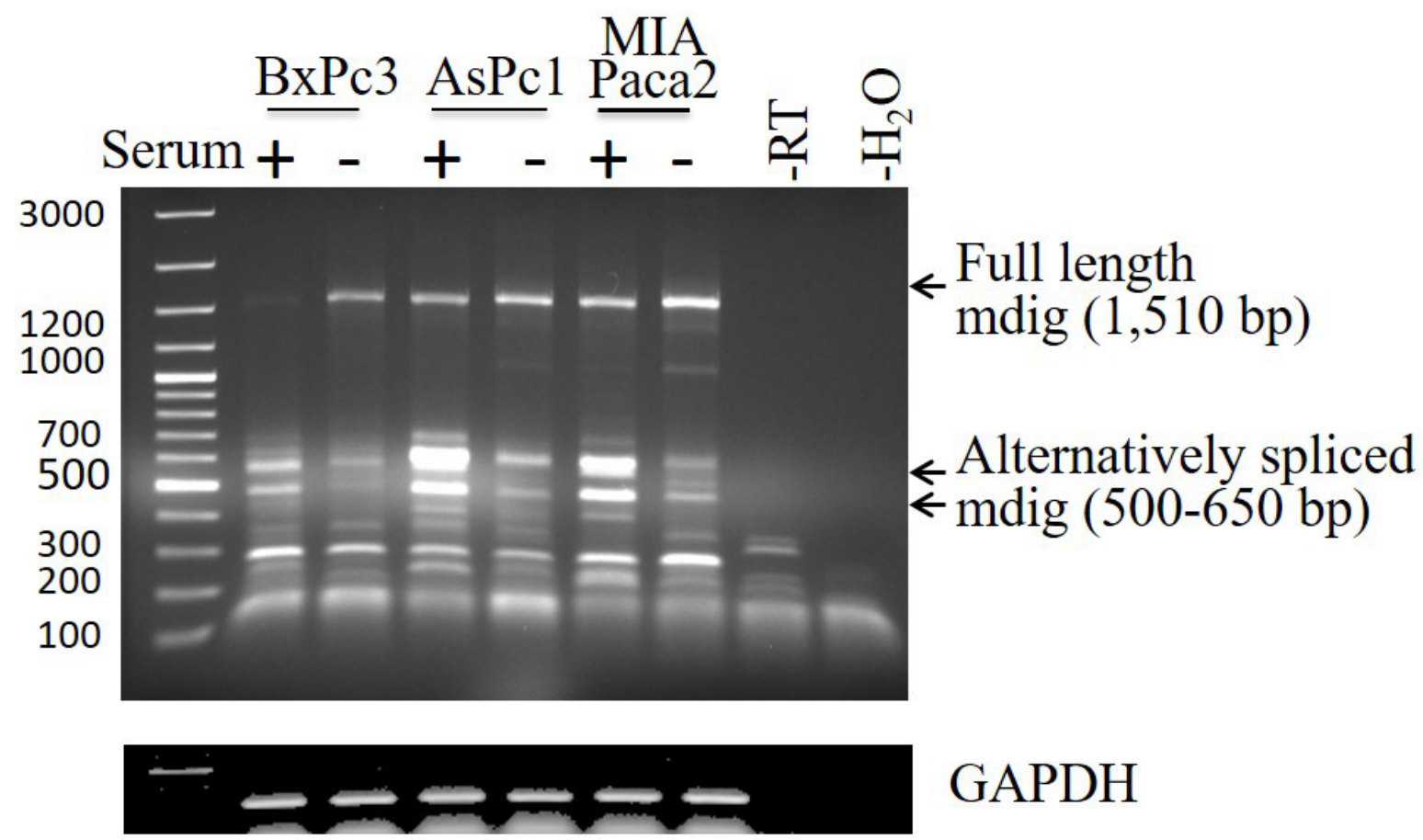

Figure 2: Expression and alternative splicing of mdig mRNA in pancreatic cancer cell line. Total RNAs from the cells cultured in the conditions as described in Figure 1. RT-PCR was performed using the primer set that amplifies full length mdig mRNA with a size of $1,510 \mathrm{bp}$. The PCR products were separated on $1 \%$ agarose gel. Arrows indicates full length and the alternatively spliced mdig mRNAs. 
mdig expression and clinicopathological variables in pancreatic cancer patients was analyzed additionally by chi-square test (Table 1). Among these variables, we found that cancer grades 2 and 3 exhibited a significantly strong mdig expression than the pancreatic cancer tissues at grade $1(p=0.03)$ (Figure 4a). No other clinicopathological variables showed a significant correlation with mdig expression. This observation is in agreement with mdig expression profiles among 130 cases containing grades 1 , 2,3 , and 4 pancreatic cancer (Figure 4b), in which grade 1 showed the lowest, and grade 4 showed the highest level of mdig expression.

\section{Correlation between exon specific mdig expression and the overall survival of pancreatic cancer patients}

Our earlier studies suggested that increased expression of mdig predicts poorer overall survival of breast cancer and lung cancer patients. Studies by other groups also indicated poorer survival of the hepatocellular carcinoma with higher level of mdig [13]. To reveal the potential prognostic value of mdig expression for the pancreatic cancer patients, we used R2 genomics visualization tool in a Mixed Tumor Pancreas (Exon) dataset to investigate the changes in the patient survival rate with respect to individual mdig exon that was detected by 19 probes provided by Affymetrix (Figure 5a). Kaplan-Meier survival graphs were generated from this data set and were compared based on their survival outcomes. Among these 19 survival analysis based on the individual probes for different exons, 15 probe sets indicated a poorer survival of the patients with higher mdig expression. However, 4 probes, probe sets 8089044 , 8089049, 8089056, and 8089058, which correspond to exon 2 , alternative exon 5 , and exon 10 , predicted better survival of the patients with higher mdig expression (Figure 5b). Since missing exon 2 and inclusion of an alternative exon 5 had been found in an alternatively spliced mdig mRNA we identified previously, the survival profiles of the different mdig exons suggested a unique or opposite role of the alternatively spliced mdig relative to the constitutive full length mdig in the pathogenesis of the pancreatic cancer.

\section{DISCUSSION}

There has been a decline in the death rate for the cancers in lung, colorectal, breast, and prostate, since
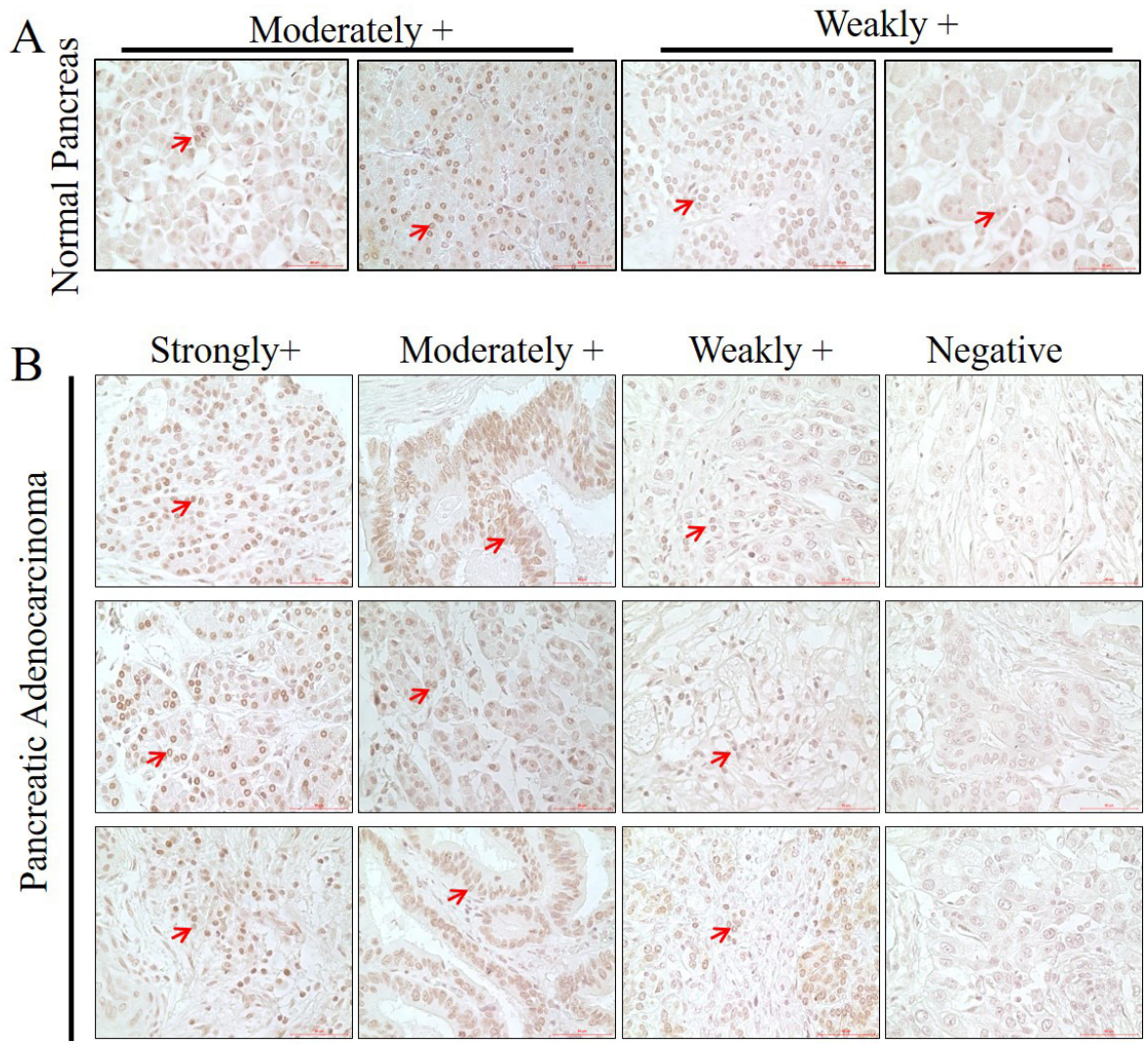

Figure 3: Immunohistochemical analysis of mdig protein in the human pancreatic tissue and pancreatic adenocarcinoma tissue microarray. Paraffin embedded tissue microarray slide was immunostained for mdig protein as described in Materials and Methods. Red arrows depict the cells positive for mdig. Scale $=50 \mu \mathrm{M}$; Magnification $=40 \mathrm{X}$. A. Normal pancreatic tissues; B. Pancreatic adenocarcinoma. 
Table 1: Expression levels of mdig and the clinicopathological variables of the pancreatic cancer patients. Pearson chisquare tests was performed to determine the $p$-value.

\begin{tabular}{|c|c|c|c|c|}
\hline \multirow{2}{*}{ Variables } & \multirow{2}{*}{ No. } & \multicolumn{2}{c|}{ Mdig expression } & \multirow{2}{*}{ P-value } \\
\cline { 3 - 4 } & & Low No. (\%) & High No. (\%) & \\
\hline Gender & & & & 0.695 \\
\hline Male & 12 & 6 & 6 & \\
\hline Female & 30 & 13 & 17 & \\
\hline Age (years) & & & & 0.118 \\
\hline$>60$ & 30 & 12 & 18 & \\
\hline$<60$ & 12 & 8 & 4 & \\
\hline Cancer grade* & & & & $\mathbf{0 . 0 3 4}$ \\
\hline 1 & 19 & 12 & 7 & \\
\hline $2 \& 3$ & 23 & 7 & 16 & \\
\hline
\end{tabular}

2003. In contrast, the death rate of pancreatic cancer was increasing in the same time period. The five year survival rate of pancreatic cancer is only about $6 \%$ since 1970 s [14]. We and others had shown an increased expression of mdig in a number of human cancers, including lung cancer, colon cancer, and breast cancer, which implies important contribution of mdig towards the pathogenesis of human cancers [11]. However, there are no reports studying the relationship of mdig expression and the clinicopathological features and/or prognosis of the pancreatic cancer. In the current study, we provide evidence showing that high level of mdig expression was a salient feature in human pancreatic cancer cell lines and tissue. By western blot analysis, we observed that all three pancreatic cancer cell lines, Bxpc3, Aspc1 and MIAPaca2, expressed high level of mdig protein, although there was a slight difference in the expression levels of mdig among these cell lines studied. Bxpc3 and MIAPaca2 showed high mdig expression levels compared to Aspc1. The RTPCR analysis showed mdig mRNA expression in all three cell lines. Interestingly, we were able to detect some strong bands of mdig mRNAs resulted from alternative splicing. The alternatively spliced mdig mRNAs might have distinctive prognostic values against the normally spliced mdig mRNA on the overall survival of the pancreatic cancer patients.

Despite extensive studies, the etiology and mechanisms of the pancreatic cancer are still elusive. Some epidemiologic studies suggested a higher incidence rate of pancreatic cancer among African Americans than Whites. Several heritable, germline mutations in p16 and/or BRCA2 may be associated with the development of pancreatic cancer [4]. It was estimated that $95 \%$ of pancreatic carcinoma showed inactivation of p16 tumor suppressor [15]. P16 is located on chromosome 9, where it encodes a protein that inhibits entry into the $\mathrm{S}$ phase of the cell cycle by inhibiting cyclin-dependent kinase (CDK) 4/6-dependent phosphorylation of retinoblastoma (RB) protein. Inactivation of p16 leads to an uncontrolled cell growth due to a fast cell cycle transition [16]. Intragenic mutation, loss of heterozygosity (LOH), homozygous deletion, and promoter hypermethylation, may be responsible for $\mathrm{p} 16$ inactivation. In addition to p16 inactivation, about $50 \%$ to $75 \%$ of pancreatic cancer show dysfunction of $\mathrm{p} 53$, one of the most important tumor suppressors [17]. As a transcription factor whose gene is located on chromosome 17, p53 regulates a variety of signaling pathways linked to cell cycle arrest, apoptosis, and DNA repair. Accordingly, functional inhibition of p53 will lead to loss of cell cycle "check-point" $[16,18]$.

Mutations in K-ras gene were frequently observed in a number of human cancers. This mutation was also found in almost all resected cases of pancreatic cancer [19]. It was believed that K-ras mutation occurs in the early stage of cancer development [20]. Because of the proximity of K-ras gene with other ras family of GTP-binding proteins on chromosome 12, genetic abnormality of K-ras gene may be additionally associated with the functional disruption of other GTP-binding proteins critical for cell growth, differentiation and survival.

Chronic pancreatitis of various types was considered as a contributing factor for about $3 \%-4 \%$ of pancreatic cancer. Apart from germline mutations or pancreatitis, other major risk factors associated with pancreatic cancer include cigarette smoking, obesity, diabetes, cirrhosis of the liver, etc. Earlier studies suggested an approximately $40 \%$ increased hazard for death of the pancreatic cancer patients who smoked cigarettes compared with those who never smoked, and risk tends to increase according to frequency or duration of smoking [5]. Dietary studies 
have shown a fairly steady pattern of increased hazard with meat or cholesterol intake and decreased risk with fruit or vegetable consumption, although causal inferences regarding these associations are still uncertain [6].

We had originally identified alternatively spliced mdig mRNAs in human cancer cell lines [7]. One of these alternatively spliced mdig mRNAs lacks the entire exon 2 region that encodes the $\mathrm{N}$-terminal and the partial JmjC regions of the mdig protein. This alternatively spliced mdig mRNA was additionally identified recently in the transformed cells induced by environmental carcinogen arsenic ( $\mathrm{Li}$, et al, unpublished observation). The JmjC domain of mdig was considered as the potential region for protein hydroxylation and/or demethylation. Loss of JmjC domain due to alternative splicing of the mdig mRNA, thus, may impair the function of mdig protein or endue new function of this protein. In pancreatic cancer cell line, such alternatively spliced mdig mRNA were also identified (Figure 2). Although it remains to be determined on the functional aspects of the alternatively spliced mdig mRNAs, the opposite prediction of the pancreatic cancer patients by the probe sets against different exons of the mdig mRNA suggests unique functions of the alternatively spliced mdig mRNAs. We are currently trying to distinguish these functional differences between the constitutively spliced full-length mdig and the alternatively spliced mdig mRNAs in both normal and cancer tissues.

In the current report, we provided evidence showing association of mdig expression and the pathogenesis of the pancreatic cancer. Previous studies suggested that increased expression of mdig predicts poor survival of the patients with breast cancer, lung cancer and hepatocellular carcinoma $[12,13,21]$. By using R2 genomics visualization tool, the probe-exon-based analysis also suggested an inverse relationship between the levels of mdig expression and the survival of the pancreatic cancer patients. However, 4 out of 19 probes showed that increased mdig expression, in fact, predicts a better overall survival of the pancreatic cancer patients, which most likely indicated a different or opposite function of the alternatively spliced mdig mRNAs. It remains to be further investigated on how different isoforms of mdig resulted from the normal and alternative splicing affect the initiation, progression and pathogenesis of the pancreatic cancer. It will also be important to determine whether mdig can serve as a biomarker for diagnosis, prognosis and molecular targeting therapy for pancreatic cancer.

\section{MATERIALS AND METHODS}

\section{Cell culture}

The human pancreatic adenocarcinoma (PA) cell line Bxpc3, Aspc1 and MIAPaca2 were purchased from the American Type Culture Collection (ATCC, Manassas, VA). Aspc1 and MIAPaca2 cells were cultured in Dulbecco's Modified Eagle's Medium - high glucose (DMEM) with 10\% fetal bovine serum (Invitrogen), 1\% penicillin-streptomycin. Bxpc3 cells were cultured in RPMI-1640 medium (HyClone) with 10\% fetal bovine serum and $1 \%$ penicillin-streptomycin and in presence of $5 \% \mathrm{CO}_{2}$.
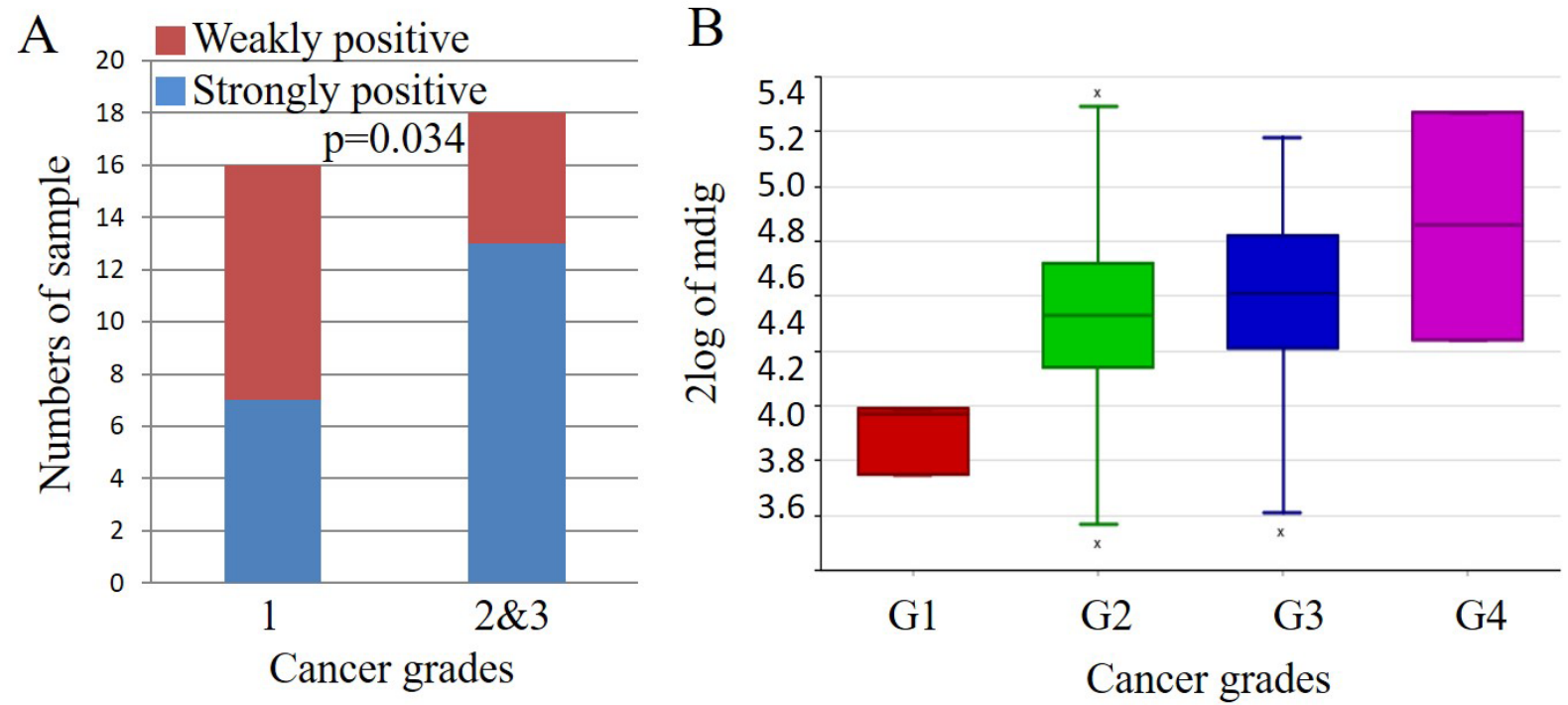

Figure 4: Association of mdig expression with the grades of pancreatic adenocarcinomas. A. Quantification of relative mdig expression in tissue microarray containing 42 cases of pancreatic adenocarcinoma tissue samples at different stages. B. Mdig expression profiles among 130 cases of pancreatic cancer at grades 1, 2, 3, and 4 as deposited in the R2: genomics database (https://hgserver1.amc.nl/ cgi-bin/r2/main.cgi). 


\section{Western blotting}

Total cellular proteins were prepared by lysing the cells in RIPA buffer (Millipore, Billerica, MA) supplemented with phosphatase/protease inhibitor cocktail and $1 \mathrm{mM}$ PMSF through sonication and centrifugation, followed by quantification using a Micro BCA Protein Assay Reagent Kit (Thermo Scientific, Pittsburgh, PA).
Before loading on 10\% SDS-PAGE gels, the proteins were boiled in LDS sample buffer (Invitrogen) containing 1 $\mathrm{mM}$ dithiothreitol. The separated proteins were transferred onto PVDF membranes (Invitrogen). Membranes were probed with the primary antibody at a dilution of 1:1000 or 1:2000 (according to signal intensity) overnight at 4 ${ }^{\circ} \mathrm{C}$. The secondary antibody with HRP was applied at the dilution of 1:2000. The mdig antibody was purchased

A

hg18:chr3

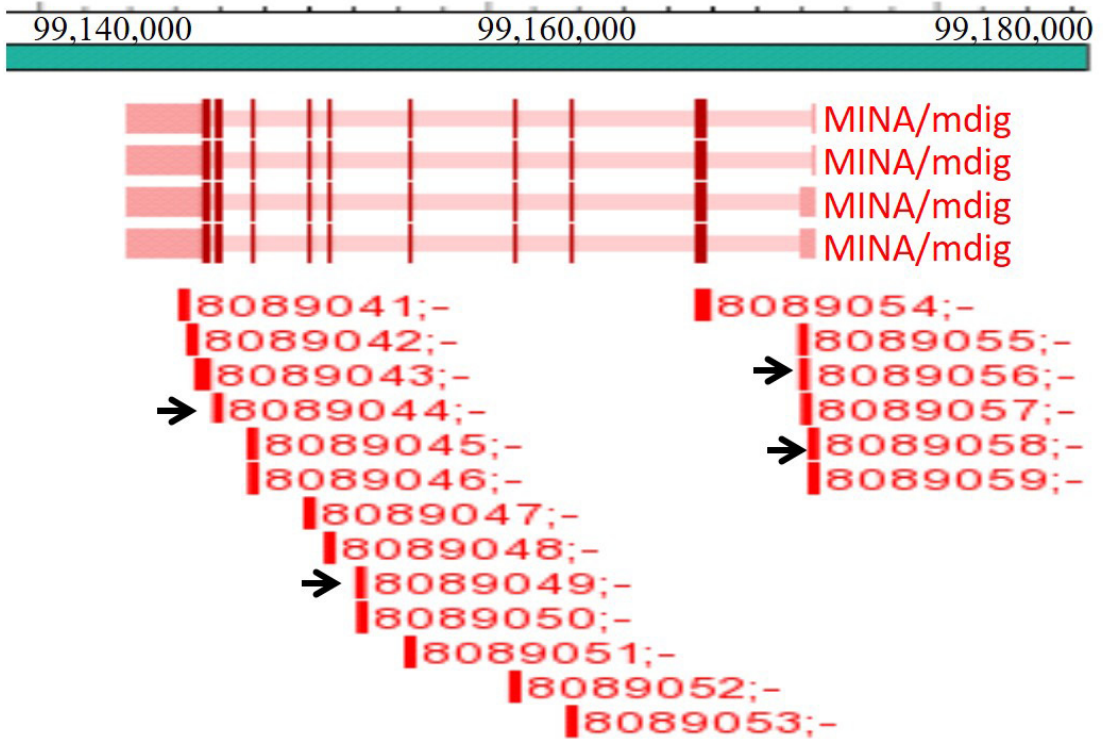

B
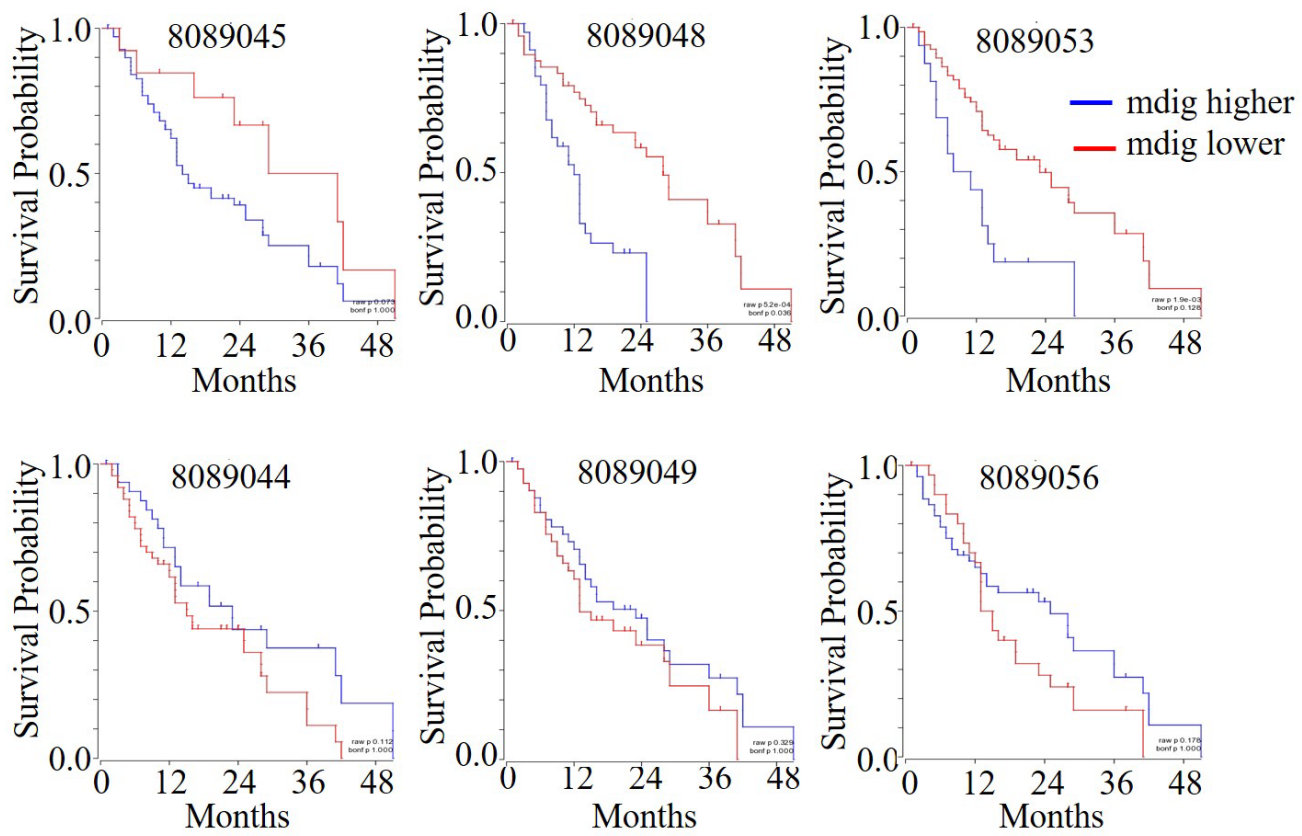

Figure 5: The levels of mdig expression predict survival of the patients with pancreatic cancer. A. Diagram of mdig gene structure and the positions of the probe detected. B. Kaplan-Meier survival analysis of the selected probe sets as indicated in the R2: Genomics Analysis and Visualization Platform database. Y axis depicts survival probability and X axis depicts months. 
from Invitrogen and GAPDH was purchased from Cell Signaling Technology, Inc.

\section{RT-PCR}

Total RNA was prepared by lysing the cells with TRIzol reagent (Invitrogen). Access Quick RT-PCR System (Promega) was used for reverse transcription and PCR. Sample composed of $1 \mu \mathrm{g}$ of total RNA and $0.3 \mu \mathrm{M}$ sense and anti-sense primer. The mdig primer sequences are: left primer: 5'-TCATGTCGGGCCTAAGAGAC-3'; right primer: 5'-GGCATTTGATTCTGCAAAGG-3', which amplify a 1509 bp cDNA fragment covering the entire coding region of the mdig mRNA. The GAPDH primer sequences are: sense: 5'-CTGAACGGGAAGCTCACTGGCATGGCCT-3'; antisense:

5'CATGAGGTCCACCACCCTGTTGCTGTAG-3'.

\section{Immunohistochemistry}

The tissue microarray slide BC14012 was purchased from US Biomax, Inc. (Rockville, MD) and deparaffinized with xylene and hydrated in series of alcohol. Slides were incubated with $1.5 \% \mathrm{H}_{2} \mathrm{O}_{2}$ for $20 \mathrm{~min}$ at room temperature, to quench the endogenous peroxidase activity. Nonspecific binding of immunoglobulin was blocked by incubating slides in a solution consisting of $5 \%$ goat serum and $0.2 \%$ triton-X 100 in PBS for $2 \mathrm{~h}$ at room temperature. Proceeded by incubation with monoclonal antibody against Mdig/Mina 53 (mouse anti-Mina 53, Invitrogen) overnight at $4{ }^{\circ} \mathrm{C}$ in 1:100 dilutions. Next day, goat antimouse biotinylated secondary antibody was applied at 1:200 dilution and incubated for $2 \mathrm{~h}$ at room temperature. Slides were then incubated with an $\mathrm{ABC}$ reagent (Vectastain Elite ABC kit) for $45 \mathrm{~min}$ at room temperature and the chromogen was developed with diaminobenzidine (DAB). Hematoxylin was used as counterstain and it was mounted with entellan. All incubation steps were carried out in a humidified chamber and all washing steps were performed with $1 \times$ PBS. Bright field optics of the Nikon Eclipse Ti-S Inverted microscope (Mager Scientific, Dexter MI, USA) was used to capture the images.

\section{Migration and invasion}

Cell migration and invasion were determined using BD BioCoat ${ }^{\mathrm{TM}}$ Matrigel $^{\mathrm{TM}}$ Invasion and Migration Chambers according to the manufacturer's instruction. After incubating for $24 \mathrm{~h}$, the cells in the upper chambers were scrubbed out using cotton tipped swab. The cells on the lower surface of the membrane were stained with the Diff-Quik Kit. The migrated and invasive cells were counted under a bright field microscope.

\section{Statistics}

The measurement errors for quantitative experiments were determined using standard deviation (SD). Comparison between mdig expression and clinicopathologic variables were determined by chi-square test. Differences with a $P$ value of $\leq 0.05$ were considered significant. Data were analyzed using IBM SPSS Statistics 22.0 (SPSS, Chicago, IL, USA). R2: Genomics Analysis and Visualization Platform (http://r2.amc.nl) a public data set was used for analyses and generation of Kaplan-Meier survival curve.

\section{Author contributions}

Conceived and designed the experiments: FC Performed the experiments: SAK, CT, LL Acquisition of data and its analysis: SAK, HC, FC Wrote the paper: SAK with supervision from FC Tools/Reagents/Research supply: FC.

\section{ACKNOWLEDGMENTS}

This work was supported by NIH grants R01 ES020137 and P30 ES020957 to FC. HC was support by the National Natural Science Foundation of China 31672496 and University Innovation Team Building Program CXTDX201601010.

\section{CONFLICTS OF INTEREST}

The authors have no conflict of interest to declare.

\section{REFERENCES}

1. Hong SM, Park JY, Hruban RH, Goggins M. Molecular signatures of pancreatic cancer. Arch Pathol Lab Med. 2011; 135: 716-27. doi: 10.1043/2010-0566-ra.1.

2. Siegel RL, Miller KD, Jemal A. Cancer Statistics, 2017. CA Cancer J Clin. 2017; 67: 7-30. doi: 10.3322/caac.21387.

3. Ferrone CR, Pieretti-Vanmarcke R, Bloom JP, Zheng H, Szymonifka J, Wargo JA, Thayer SP, Lauwers GY, Deshpande V, Mino-Kenudson M, Fernández-del Castillo C, Lillemoe KD, Warshaw AL. Pancreatic ductal adenocarcinoma: Long-term survival does not equal cure. Surgery. 2012; 152: S43-9. doi: 10.1016/j.surg.2012.05.020.

4. Hruban RH, Petersen GM, Goggins M, Tersmette AC, Offerhaus GJ, Falatko F, Yeo CJ, Kern SE. Familial pancreatic cancer. Ann Oncol. 1999; 10 Suppl 4: 69-73.

5. Yuan C, Morales-Oyarvide V, Babic A, Clish CB, Kraft P, Bao Y, Qian ZR, Rubinson DA, Ng K, Giovannucci EL, Ogino S, Stampfer MJ, Gaziano JM, et al. Cigarette Smoking and Pancreatic Cancer Survival. Journal of Clinical Oncology. 0: JCO.2016.71.26. doi: 10.1200/ 
jco.2016.71.2026.

6. Risch HA. Etiology of pancreatic cancer, with a hypothesis concerning the role of $\mathrm{N}$-nitroso compounds and excess gastric acidity. J Natl Cancer Inst. 2003; 95: 948-60.

7. Zhang Y, Lu Y, Yuan BZ, Castranova V, Shi X, Stauffer JL, Demers LM, Chen F. The Human mineral dust-induced gene, mdig, is a cell growth regulating gene associated with lung cancer. Oncogene. 2005; 24: 4873-82. doi: 10.1038/ sj.onc. 1208668 .

8. Tsuneoka M, Koda Y, Soejima M, Teye K, Kimura H. A novel myc target gene, mina53, that is involved in cell proliferation. J Biol Chem. 2002; 277: 35450-9. doi: 10.1074/jbc.M204458200.

9. Eilbracht J, Kneissel S, Hofmann A, Schmidt-Zachmann MS. Protein NO52 - a constitutive nucleolar component sharing high sequence homologies to protein NO66. Eur J Cell Biol. 2005; 84: 279-94. doi: 10.1016/j. ejcb.2004.12.022.

10. Yu M, Sun J, Thakur C, Chen B, Lu Y, Zhao H, Chen F. Paradoxical roles of mineral dust induced gene on cell proliferation and migration/invasion. PLoS One. 2014; 9: e87998. doi: 10.1371/journal.pone.0087998.

11. Thakur C, Chen F. Current understanding of mdig/MINA in human cancers. Genes Cancer. 2015; 6: 288-302. doi: 10.18632/genesandcancer.73.

12. Chen B, Yu M, Chang Q, Lu Y, Thakur C, Ma D, Yi Z, Chen F. Mdig de-represses H19 large intergenic noncoding RNA (lincRNA) by down-regulating H3K9me3 and heterochromatin. Oncotarget. 2013; 4: 1427-37.

13. Huo Q, Ge C, Tian H, Sun J, Cui M, Li H, Zhao F, Chen T, Xie H, Cui Y, Yao M, Li J. Dysfunction of IKZF1/MYC/ MDIG axis contributes to liver cancer progression through regulating H3K9me3/p21 activity. Cell Death Dis. 2017; 8: e2766. doi: 10.1038/cddis.2017.165.

14. Shin EJ, Canto MI. Pancreatic Cancer Screening. Gastroenterol Clin North Am. 2012; 41: 143-57. doi: 10.1016/j.gtc.2011.12.001.

15. Li D, Xie K, Wolff R, Abbruzzese JL. Pancreatic cancer. Lancet. 2004; 363: 1049-57. doi: 10.1016/s01406736(04)15841-8.

16. Sirivatanauksorn V, Sirivatanauksorn Y, Lemoine NR. Molecular pattern of ductal pancreatic cancer. Langenbecks Arch Surg. 1998; 383: 105-15.

17. Goggins M. Molecular markers of early pancreatic cancer. J Clin Oncol. 2005; 23: 4524-31. doi: 10.1200/ jco.2005.19.711.

18. Rivlin N, Brosh R, Oren M, Rotter V. Mutations in the p53 Tumor Suppressor Gene: Important Milestones at the Various Steps of Tumorigenesis. Genes Cancer. 2011; 2: 466-74. doi: 10.1177/1947601911408889.

19. Sakorafas GH, Tsiotou AG, Tsiotos GG. Molecular biology of pancreatic cancer; oncogenes, tumour suppressor genes, growth factors, and their receptors from a clinical perspective. Cancer Treat Rev. 2000; 26: 29-52. doi: 10.1053/ctrv.1999.0144.

20. Deramaudt T, Rustgi AK. Mutant KRAS in the initiation of pancreatic cancer. Biochim Biophys Acta. 2005; 1756: 97-101. doi: 10.1016/j.bbcan.2005.08.003.

21. Thakur C, Lu Y, Sun J, Yu M, Chen B, Chen F. Increased expression of mdig predicts poorer survival of the breast cancer patients. Gene. 2014; 535: 218-24. doi: 10.1016/j. gene.2013.11.031. 